\title{
Prevalence of Hydatid Cyst in Slaughtered Livestock in Kermanshah (West Iran)
}

\author{
Reza Faraji' ${ }^{1}$, Gholam Reza Javadi², Parisa Mohamadi Barshahi' ${ }^{3}$, Fereshte Ahmadian4, \\ Mohammadtaghi Sarebanhassanabadi'1, Ali Dehghani Firoozabadi', \\ Abdol Rasoul Moloudi ${ }^{*}$ \\ ${ }^{1}$ Yazd Cardiovascular Research Center, Shahid Sadoughi University of Medical Sciences, Yazd, Iran \\ ${ }^{2}$ Shahrekord University of Medical Sciences, Shahrekord, Iran \\ ${ }^{3}$ Department of Biostatistics and Epidemiology, Kermanshah University of Medical Sciences, \\ Kermanshah, Iran \\ ${ }^{4}$ Clinical Biochemistry, International Campus, Shahid Sadoughi University of Medical Sciences, Yazd, Iran \\ ${ }^{5}$ Department of Cardiovascular Surgery, Imam Ali Heart Center, Kermanshah University of Medical Sciences, \\ Kermanshah, Iran \\ Email: ${ }^{*}$ amoloudi@yahoo.com
}

Received 11 February 2015; accepted 7 April 2015; published 9 April 2015

Copyright (C) 2015 by authors and Scientific Research Publishing Inc.

This work is licensed under the Creative Commons Attribution International License (CC BY).

http://creativecommons.org/licenses/by/4.0/

(c) (i) Open Access

\begin{abstract}
Background: Hydatidosis or echinococcosis is one of the most important economic and public health problems in many regions of the world that livestock are kept such as Iran. This study was to determine the prevalence of hydatid cyst in slaughtered livestock in Kermanshah (west Iran) (2012). Methods: This descriptive-analytic study was carried out on all slaughtered livestock during 24 months period, from March 2012 until February 2013. 70,020 carcasses were observed and inspected (including: 24,507 cattle, 35,010 sheep and 10,503 goats). All cysts were examined under direct microscopy for determine the kind of cysts (fertile and infertile cyst). Results: The prevalence of hydatid cyst was $2.20 \%$ in cattle, $2.78 \%$ in sheep and $0.19 \%$ in goat. Liver in cattle with $1.42 \%$, in sheep with $2.25 \%$, and in goat with $0.13 \%$ was contaminated. Also lung in cattle with $0.76 \%$, in sheep with $0.53 \%$, and in goat with $0.06 \%$ was contaminated. Heart was contaminated only in cattle with $0.024 \%$. Sheep with $45 \%$ and goat with $90.47 \%$ had highest fertile cyst and infertile cyst, respectively. Conclusion: The prevalence rate of hydatid cyst in slaughtered livestock in Kermanshah was lowest, as compared with other regions of Iran. Despite this, hygienic programs should be done in order to decrease, control and prevent of parasitic infection.
\end{abstract}

\section{Keywords}

Hydatid Cyst, Slaughtered Livestock, Iran

\footnotetext{
${ }^{*}$ Corresponding author.
} 


\section{Introduction}

Hydatidosis is a one of the zoonotic disease between humans and animals that has a significant position among parasite infections. Hydatid disease is caused by the larvae stage of tape worm Echinococcus granulosus. It's also called echinococcosis. Hydatid is not directly transmitted from person to person. It has two mammalian hosts in the lifecycle. Sheep and dogs acts as intermediate and definitive hosts of the cystic stages of these tapeworms, respectively. Dogs defecate outside, and further spread may be via streams, effluent or flies. Tiny eggs are excreted into the environment. Sheep have a highly resistant against new cysts but this has little effect on existing cysts. The cycle is perpetuated as dogs eaten carcasses of infected sheep. Small hydatid cysts are different with large hydatid cysts, so that large hydatid cysts are very resilient but small cysts are susceptible to desiccation. Grows of cysts are slowly $(5-10 \mathrm{~cm}$ ) in the internal organs, especially livers and lungs (occasionally the brain, heart, spleen, kidney or bones). The disease may take many years to develop or decades without symptoms and often are detected incidentally. Local pressure effects in a confined space may lead to symptoms. Rarely, cysts rupture into the biliary tree or a bronchus causing obstruction, secondary bacterial infection, an allergic reaction or secondary spread. The most favourable for survival are moist conditions and cool. Freezing is not suitable to kill a significant number of cysts [1]-[3]. Humans do not play a role in the biological cycle although they are intermediate hosts and may act as agents in perpetuating the infection by feeding dogs with infected meat and viscera. Infections in humans' occur by ingesting eggs through hand to mouth transfer of eggs after contact with the faeces or contaminated fur of infected dogs. In humans diagnosis are by serological and molecular techniques, imaging, and clinical. But in animals hydatidosis no specific signs in farm [4]. In humans, the disease is so serious that it requires aspiration and surgical removal of the cyst followed by complementary chemotherapy with mebendazole or albendazole. Control programs for hydatid disease have been on public education, restrictions on livestock slaughtering and control measures in dogs [5] [6]. Also vaccination of livestock with effective vaccine could be one of the control methods for hydatid cyst. This disease is domestic in various parts of the world, like the Middle East and Arabic North Africa [7]-[9]. So that hydatidosis is one of the dynamic programs of World Health Organization in the field of zoonotic disorders [10]. According to the past study that carried out in Iran, hydatidosis is domestic [7] [10]-[15]. As regards diagnosis in livestock detected at slaughter or at post mortem examination, therefore this study was to determine the prevalence of hydatid cyst in slaughtered livestock in Kermanshah (west Iran) (2012).

\section{Materials and Methods}

This descriptive-analytic study was carried out on all slaughtered livestock during 24 months period, from March 2012 until February 2013. 70,020 carcasses were observed and inspected (including: 24,507 cattle, 35,010 sheep, and 10,503 goats). Livestock informations such as: livestock type (cattle, sheep, and goat), age (determination by teeth examination), sex, race, and livestock whereabouts were recorded. After slaughter, carcasses were numbered and after discharging offal, carcasses contaminated with hydatid cyst were investigated. Infected organs were removed during slaughterhouse and record the consumption cycle. In order to study the cyst, they are sent to the research laboratory of parasitology, and cut cyst with a scalpel, then absterge with saline 9 per 1000. With loops and direct microscopy kind of cyst was specified (fertile and infertile cyst). Fertile cyst (with protoscoleces and brood capsules) have the inner germinal layer thin but infertile cyst (without protoscoleces) have a thick smooth inner [16] [17].

\section{Results}

In this study 70,020 carcasses were observed and inspected (including: 24,507 cattle, 35,010 sheep and 10,503 goats). The mean age was 7 year ( $\mathrm{SD}=7$ ) with age from 12 months to 180 months. From 70,020 carcasses 63\% were males and $37 \%$ were females. $66 \%$ were native race and $34 \%$ non-native race. The prevalence of hydatid cyst was $2.20 \%$ in cattle, $2.78 \%$ in sheep, and $0.19 \%$ in goat. Liver in cattle with $1.42 \%$, in sheep with $2.25 \%$, and in goat with $0.13 \%$ was contaminated (Figure 1). Also lung in cattle with $0.76 \%$, in sheep with $0.53 \%$, and in goat with $0.06 \%$ was contaminated (Figure 2). Heart was contaminated only in cattle with $0.024 \%$ (Figure 3 ) (Table 1). Sheep with $45 \%$ and goat with $90.47 \%$ had highest fertile cyst and infertile cyst, respectively (Table 2). 


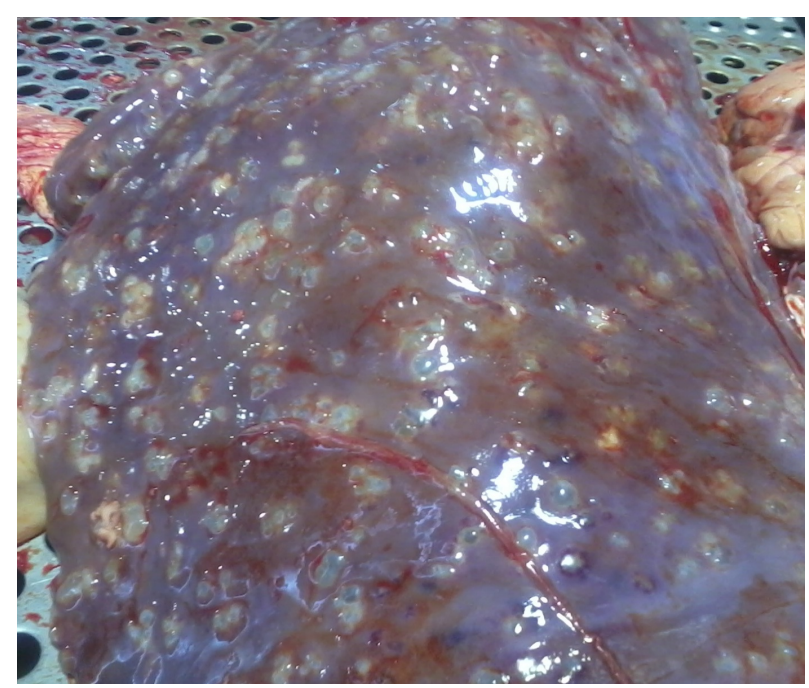

Figure 1. Contamination liver to hydatid cyst according to contaminated organ.

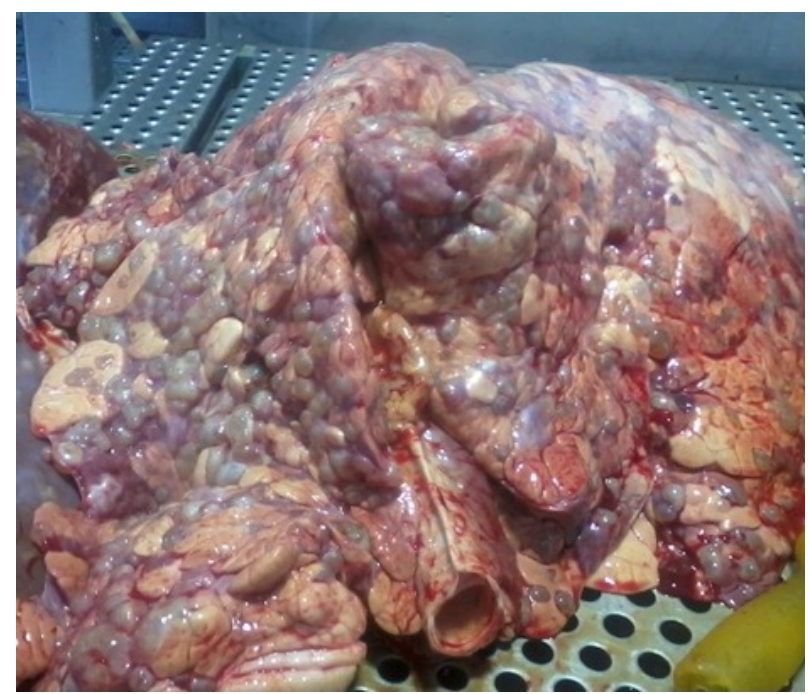

Figure 2. Contamination lung to hydatid cyst according to contaminated organ.

\section{Discussion}

Hydatidosis is one of the most important zoonotic diseases that distribute in the most area of the world. It's endemic in Iran, and makes a lot of economic damage. The disease has no specific symptoms. And the most diagnosis, especially in the intermediate hosts (sheep) occurs on slaughterhouse carcasses. So slaughterhouses are only and sure location for diagnosis. Because the liver and lung lesions are mostly visible with the naked eye and are distinguishable. And according it infected organs are removed [7] [18]-[21]. In this study 70,020 carcasses (including: 24,507 cattle, 35,010 sheep and 10,503 goat) were observed and inspected. The prevalence of hydatid cyst was $2.20 \%$ in cattle, $2.78 \%$ in sheep, and $0.19 \%$ in goat. Therefore in this study sheep with $2.78 \%$ was more contaminated than cattle and goats. In a study by Scala et al. that to do in Italy in 2006 the prevalence rate of hydatid cyst 75\% reported [22]. Also Saeed et al. during the period 1990-1998, 1270 sheep, 550 goats and 320 cattle were examined at slaughter for hydatid cysts and prevalence rates were found to be $15.0 \%, 6.2 \%$ and $10.9 \%$, respectively [23]. In the Scala and Saeed studies like our study, the highest frequency of cysts was in sheep. But in the Rostami Nejad et al. study that performed on 6993 cattle, 14,084 sheep, and 19,354 goats during a 5-year period from 2002 to 2006 in Lorestan province (Aleshtar) located in South-West of Iran, 26.71\% of 


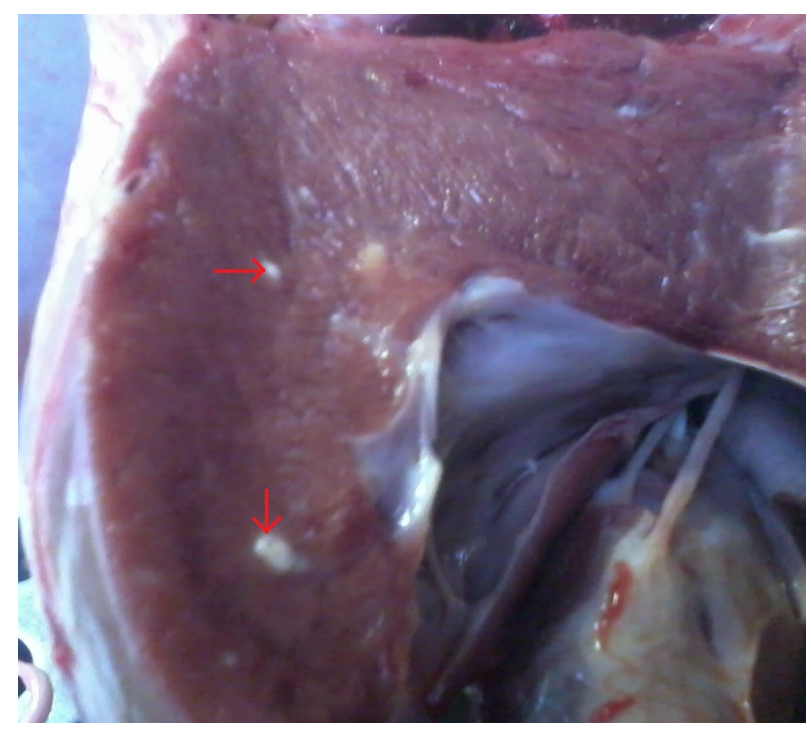

Figure 3. Contamination heart to hydatid cyst according to contaminated organ.

Table 1. Contamination abundance of hydatid cyst according to contaminated organ in examined carrions in the slaughterhouse of Kermanshah (west Iran) in 2012.

\begin{tabular}{|c|c|c|c|c|c|c|c|c|}
\hline \multirow{3}{*}{ Type } & \multirow{3}{*}{ Slaughtered No. } & \multirow{3}{*}{$\%$} & \multicolumn{6}{|c|}{ Contaminated organ } \\
\hline & & & \multicolumn{2}{|c|}{ Liver } & \multicolumn{2}{|c|}{ Lung } & \multicolumn{2}{|c|}{ Heart } \\
\hline & & & No. & $\%$ & No. & $\%$ & No. & $\%$ \\
\hline Cattle & 24507 & 2.20 & 348 & 1.42 & 187 & 0.76 & 6 & 0.024 \\
\hline Sheep & 35010 & 2.78 & 789 & 2.25 & 185 & 0.53 & 0 & 0 \\
\hline Goat & 10503 & 0.19 & 14 & 0.13 & 7 & 0.06 & 0 & 0 \\
\hline
\end{tabular}

Table 2. Contamination abundance of hydatid cyst according to fertility and infertility status of the cysts in examined carrions in the slaughterhouse of Kermanshah (west Iran) in 2012.

\begin{tabular}{rccccc}
\hline & & \multicolumn{3}{c}{ Cyst status } \\
\cline { 3 - 6 } Type & Meat inspection No. & \multicolumn{2}{c}{ Fertile cyst } & \multicolumn{2}{c}{ Infertile cyst } \\
\cline { 3 - 6 } & & No. & $\%$ & No. & $\%$ \\
\hline Cattle & 541 & 139 & 25.69 & 398 & 73.56 \\
Sheep & 974 & 438 & 45 & 536 & 55 \\
Goat & 21 & 2 & 9.52 & 19 & 90.47 \\
\hline
\end{tabular}

cattle, $21.22 \%$ of sheep and $12.97 \%$ of goats were infected by hydatid cyst [7]. In other study by Hazrati Tappe, of 4564 livestock studied 245 (5.4\%) were infected by Echinococcus granolosus, among them, 2.7\% were sheep, 8.6\% were cattle, and $12.9 \%$ were water buffalos [10]. In Rostami Nejad and Hazrati Tappe studies unlike our study the highest frequency of cysts was in cattle. As regards cattle, sheep, and goat were intermediate hosts, but sheep is the important role in hydatid life cycle. In this study liver in cattle with $1.42 \%$, in sheep with $2.25 \%$, and in goat with $0.13 \%$ was contaminated. Also lung in cattle with $0.76 \%$, in sheep with $0.53 \%$, and in goat with $0.06 \%$ was contaminated. Heart was contaminated only in cattle with $0.024 \%$. Studies on 844,039 animals (131,716 cattle, 577,090 sheep and 135,233 goats) slaughtered in the 5-year period in Shiraz, Iran showed that 4.1\% livers and 14.62\% lungs were condemned [14]. In Rostami Nejad et al. study 7.13\% lungs and 7.13\% livers and 3.95\% peritoneal cavity were contaminated by hydatid cyst [7]. In Saeed et al. study between 63\% and 82\% livers and between $72 \%$ and 79\% lungs were contaminated [23]. Molan in his study that performed on sheep, 
liver with $6.5 \%$ and lung with 3.8 were infected [24]. Survey of these studies show that it seems the fertility and infertility of cyst is one of the main factors that could influence contamination proportion in different organs. So that in our study, the fertility rates of hydatid cyst in examined animals were as follows: in sheep, it was $45 \%$; in cattle, it was $25.69 \%$; and in goat, it was $9.52 \%$. Also most infertile cysts with $90.47 \%$ were in goat and in sheep and cattle were $55 \%$ and $73.56 \%$, respectively. These statistics indicate a low level of fertility cysts that can be due to factors such as: mountainous and cold and livestock grazing on rangeland is in poor area that affected on the activity cycle of the Echinococcus granulosus. Like our study in Saeed study fertility of sheep cysts, i.e. those containing protoscoleces, was found to be significantly higher (64\%) than that of goats (35.7\%) and cattle (29.8\%) (23). In other study by Anwar et al. fertility of sheep cysts was $80.95 \%$ and fertility of cattle cysts was $65.45 \%$ [25]. Study results above indicate fertility cysts in sheep. Fertility cysts have generating layer and protoscoleces. While most cysts of cattle, were sterilized. This can lead to high safety and immune in cattle compared sheep. Therefore the sheep could have an important role in maintaining the life cycle of the parasite. Recommended control programs that carried out for this disease with more sensitively focused on the sheep.

\section{Conclusion}

Using abattoir based data, this study indicates that Kermanshah has the lowest prevalence of hydatidosis among different Iranian population and the rate of hydatid cysts decrease in cattle, sheep, and goat according to this data analysis. That it could be indicated the appropriate control measures associated with low levels of contamination.

\section{Acknowledgements}

The authors sincerely appreciate the Kermanshah University of Medical Sciences and Department of inspection slaughterhouse of Bistoons Kermanshah (west Iran).

\section{References}

[1] Sabzi, F., Ghasemi, F., Madani, H. and Faraji, R. (2013) Hydatid Cyst of the Right Atrium Wall. EMHJ, 19, S220S223.

[2] Sabzi, F. and Faraji, R. (2013) A Giant Hydatid Cyst in the Interventricular Septum with Papillary Muscle Involvement. The Korean Journal of Parasitology, 51, 349-352. http://dx.doi.org/10.3347/kjp.2013.51.3.349

[3] Sabzi, F. and Faraji, R. (2014) Hydatid Cyst of the Interventricular Septum Causing Complete Heart Block and Postoperative Ventricular Septal Defect. IJCCM, 18, 473-475.

[4] Palmer, S.R., Biffin, A.H.B., Craig, P.S. and Walters, T.M.H. (1996) Control of Hydatid Disease in Wales. BMJ, 312, 674-675. http://dx.doi.org/10.1136/bmj.312.7032.674

[5] Paykari, H., Karimi, Gh.R., Motamedi, Gh.R., Abshar, N. and Navidpour, S. (2007) A Serological Survey for Hydatidosis among Buffaloes in Orumia. Archives of Razi Institute, 62, 101-104.

[6] Paykari, H., Heath, D.D., Dalimi, A.H., Karimi, Gh.R. and Motamedi, Gh.R. (2008) Experimental Vaccination of Sheep against Hydatid Cyst Using EG95 Recombinant Vaccine. Archives of Razi Institute, 63, 29-34.

[7] Rostami Nejad, M., Jahani-Sherafat, S., Cheraghipour, K., Nazemallhoseini Mojarad, E., Taghipour, N. and Zali, M.R. (2012) Hydatic Cyst Prevalence in Slaughtered Animals, a Neglected Health Problem. JPS, 3, 2008-4978.

[8] Rostami Nejad, M., Nazemalhosseini Mojarad, E. and Fasihi Harandi, M. (2010) Echinococcosis: Based on Molecular Studies in Iran. Gastroenterology and Hepatology from Bed to Bench, 3, 169-176.

[9] Romig, T. (2003) Epidemiology of Echinococcosis. Langenbeck’s Archives of Surgery, 388, 17-209. http://dx.doi.org/10.1007/s00423-003-0413-3

[10] Hazrati Tappe, K., Mousavi, S.J. and Barazesh, A. (2011) Prevalence and Fertility of Hydatid Cyst in Slaughtered Livestock of Urmia City, Northwest Iran. Journal of Parasitology and Vector Biology, 3, 29-32.

[11] Tavakoli, H.R., Bayat, M. and Kousha, A. (2008) Hydatidosis Infection Study in Human and Livestock Populations during 2002-2007. American-Eurasian Journal of Agricultural \& Environmental Sciences, 4, 473-477.

[12] Ahmadi, N.A. and Meshkehkar, M. (2010) Prevalence and Long Term Trend of Liver Fluke Infections in Sheep, Goats and Cattle Slaughtered in Khuzestan, Southwestern Iran. JPS, 1, 26-31.

[13] Hosseini, S.H. and Eslami, A. (1998) Morphological and Developmental Characteristics of Echinococcus granulosus Derived from Sheep, Cattle and Camels in Iran. Journal of Helminthology, 72, 337-341. 
http://dx.doi.org/10.1017/S0022149X00016709

[14] Ansari-Lari, M. (2005) A Retrospective Survey of Hydatidosis in Livestock in Shiraz, Iran Based on Abattoir Data during 1999-2004. Veterinary Parasitology, 133, 119-123. http://dx.doi.org/10.1016/j.vetpar.2005.05.031

[15] Daryani, A., Alaei, R., Arab, R., Sharif, M., Dehghan, M.H. and Ziaei, H. (2006) Prevalence of Liver Fluke Infections in Slaughtered Animals in Ardabil Province. Journal of Animal and Veterinary Advances, 5, 408-411.

[16] Bortoletti, G., Gabriele, F. and Seu, V. (1990) Epidemiology of Hydatid Disease in Sardines. Journal of Helminthology, 64, 216-212. http://dx.doi.org/10.1017/S0022149X00012189

[17] Ellis, J.A., Chavera, A.E.V. and DeMartini, J.C. (1993) Disease Conditions in Slaughtered Sheep from Small Holder Flocks in Peru. Small Ruminant Research, 10, 243-250. http://dx.doi.org/10.1016/0921-4488(93)90129-6

[18] Sadjjadi, S.M., Ardehali, S., Noman-Pour, B., Kumar, V. and Izadpanah, A. (2001) Diagnosis of Cystic Echinococcosis: Ultrasound Imaging or Countercurrent Immunoelectrophoresis. The Eastern Mediterranean Health Journal, 7, 907-911.

[19] Chow, C., Gauci, C.G., Vural, G., Jenkins, J.J., Heath, D.D., Rosenzvit, M.C., Harandi, M.F. and Lightowlers, M.W. (2008) Echinococcus granulosus: Variability of the Host-Protective EG95 Vaccine Antigen in G6 and G7 Genotypic Variants. Experimental Parasitology, 119, 499-505. http://dx.doi.org/10.1016/j.exppara.2008.01.004

[20] Sadjjadi, S.M. (2006) Present Situation of Echinococcosis in the Middle East and Arabic North Africa. Parasitology International, 55, S197-S202. http://dx.doi.org/10.1016/j.parint.2005.11.030

[21] Ito, A., Okamoto, M., Li, T., Wandra, T., Dharmawan, N.S., Swastika, K.I., Dekumyoy, P., Kusolsuk, T., Davvajav, A., Davaasuren, A., Dorjsuren, T., Mekonnen, S.M., Negasi, Z.H., Yanagida, T., Sako, Y., Nakao, M., Nakaya, K., Lavikainen, A.J., Nkouawa, A. and Mohammadzadeh, T. (2011) The First Workshop towards the Control of Cestode Zoonoses in Asia and Africa. Parasites \& Vectors, 4, 114. http://dx.doi.org/10.1186/1756-3305-4-114

[22] Scala, A., Garippa, G., Varcasia, A. and Tranquilloand, V.M. (2006) Cystic Echinococcosis in Slaughtered Sheep in Sardinia (Italy). Veterinary Parasitology, 135, 33-38. http://dx.doi.org/10.1016/j.vetpar.2005.08.006

[23] Saeed, I., Kapel, C., Saida, L.A., Willingham, L. and Nansen, P. (2000) Epidemiology of Echinococcus granulosus in Arbil Province, Northern Iraq, 1990-1998. Journal of Helminthology, 74, 83-88. http://dx.doi.org/10.1017/S0022149X00000111

[24] Molan, A.L. (1993) Epidemiology of Hydatidosis and Echinococcosis Theqar Province Southern Iraq. Japanese Journal of Medical Science and Biology, 46, 29-35. http://dx.doi.org/10.7883/yoken1952.46.29

[25] Anwar, A.H., Haq, A.U., Gill, S.A. and Chaudhry, A.H. (1993) Prevalence and Fertility Ratio of Hydatid Cyst in Slaughtered Sheep and Goats at Faisalabad. Pakistan Veterinary Journal, 13, 79-81. 